\title{
Technological innovations and hospital performance: a systematic review of the literature
}

This article was published in the following Dove Press journal:

Innovation and Entrepreneurship in Health

8 December 2014

Number of times this article has been viewed

\author{
Ferhat D Zengul' \\ Robert Weech-Maldonado' \\ Grant T Savage ${ }^{2}$ \\ 'Department of Health Services \\ Administration, ${ }^{2}$ Department of \\ Management, Information Systems and \\ Quantitative Methods, University of \\ Alabama at Birmingham, Birmingham, \\ $\mathrm{AL}$, USA
}

\begin{abstract}
Given the ongoing concerns about health care quality and costs during the 21st century, significant attention has been focused on the clinical and financial performance of US hospitals. On one hand, hospitals have been adopting various clinical technologies to improve their clinical quality and financial performance. On the other hand, there is no comprehensive study that has examined the research evidence on the relationship between clinical high technology and hospital performance (clinical and financial). This systematic literature review attempts to account for the technology-performance link in US hospitals by focusing on clinical technologies and services. The review confirms the paucity of research on this topic and reveals that there are mixed findings across research studies. It also provides directions and recommendations for future research by identifying major gaps in the existing literature.
\end{abstract}

Keywords: clinical performance, financial performance, hospital technology, quality

\section{Introduction}

US hospitals have been facing increasing challenges to improve their clinical and financial performance. Some of these challenges arise from efforts to control increasing hospital costs. As a result of legislative pressures, pay-for-performance initiatives, quality-enhancement measures, and various other external pressures, hospitals are searching for ways to improve their performance. Since technology represents a high proportion of hospital capital investments, it has long been identified as a major contributor to both clinical and financial performance.

Hospital technology, for the purposes of this paper, is defined as high-technology clinical equipment and services that are designed to solve certain human health problems, to improve human health conditions, or to improve the precision of diagnosis (eg, high-tech medical/surgical intensive care, electron beam computed tomography, etc). ${ }^{1}$ About $50 \%$ of hospital capital investment is spent on technology-improvement initiatives. ${ }^{2}$ Importantly, the adoption of new technologies, including both big- and small-ticket items, and the increased use of existing technologies are responsible for $30 \%-75 \%$ of the health care costs in the United States. ${ }^{2-7}$ Technological advancements also are a major contributor to better clinical performance in hospitals. For example, hospital technologies such as minimally invasive surgeries and cardiac catheterization have improved quality of care by reducing recovery time and mortality rates. ${ }^{8,9}$

There are significant challenges for researchers who want to investigate the causal links between hospital technology and clinical and financial performance. Exploring this relationship is not a trivial exercise. It requires, among other factors, accounting for the socioeconomic and demographic variance among patients, the variances in 
payers' reimbursement and regulatory policies, as well as the various diseases diagnosed and treated by hospitals. Given the complexity of the health care context and the complexity of the relationship between hospital technology and performance, we believe it is critical to evaluate the state of existing research to determine the knowledge gaps and inform future research agendas.

This study addresses this need by systematically reviewing the literature on the relationship between hospital technology and performance. In this study, hospital performance refers to both clinical and financial performance. This review focuses only on clinical technologies and services; health information technology, with its own substantial body of research, is outside the scope of this study. When adopting new clinical technologies, hospital decision makers focus on two rationales: the expected improvement in clinical performance, and the expected positive impact on financial performance. Therefore, the intent of this literature review is to provide systematically aggregated information on the clinical and financial performance implications of clinical technologies for hospital decision makers.

To better inform hospital executives, we focus on organizational-level performance, rather than departmentalor unit-level performance, for two reasons. First, although there are a large number of studies that focus on individual clinical technologies and departmental-level performances (eg, cost-benefit analyses of individual technologies), these studies typically do not look at the organizational implications of high-tech services. Second, organizational performance does not only depend upon unit/departmental performance, but also on other factors (eg, external competition, regulatory costs, unfunded legislative mandates, etc). In other words, organizational performance cannot be defined as the aggregate of various departments' performances; rather, organizational performance is achieved through the interaction of technologies with individuals, departments, other organizations, and various other external forces, including both governmental and other regulatory bodies.

\section{New contribution}

This review examines the empirical studies that have investigated the impact of hospital technologies on organizational performance, both clinical and financial. There are four ways in which this review differs from previous reviews on this topic. First, it particularly focuses on high-tech clinical services and attempts to account for the relationship between these services and hospital performance. In this review, hospital performance is considered a dependent variable and technology an independent variable. Most other studies (eg, diffusion of innovation or technology adoption studies) ${ }^{10-19}$ have focused on technology as the dependent variable. By focusing on technology as an independent variable, this review attempts to bring attention to this less explored area of study while also viewing technology as a strategic asset. Second, it addresses a need to evaluate the strategic implications of high-tech services, accomplished by focusing on organizational-level performance rather than unit- or departmental-level performance. Third, this review draws upon Spetz and Maiuro's ${ }^{1}$ typology (focused on hospital technology measurement) and extends it by focusing on the relationship between hospital technology and performance. Finally, this review integrates traditional literature review processes (eg, manual searches of bibliographies) with a systematic review process to improve its comprehensiveness.

\section{Analytical framework}

As seen in Figure 1, the main objective of this review is to examine the relationship between hospital technology and organizational performance (clinical/financial). Especially for the clinical performance dimension of our analytical framework, this review is informed by Donabedian's structure-process-outcome framework. ${ }^{20-22}$ We emphasized the technology-clinical performance (quality) link in our framework since the impact of technology is considered within the structure dimension of Donabedian's structureprocess-outcome framework. The rest of the details of this analytical framework are based on the following four main research questions:

1. What are the major findings in regards to the relationship between hospital technology and financial/clinical quality performance?

2. What types of research designs were used in these studies?

3. What types of hospital technology measures were used in these studies?

4. What types of hospital financial/quality performance measures were used?

\section{Methods}

The search process included several steps. First, we identified relevant papers as those that were US-based empirical peer-reviewed studies that investigated the relationship between high-tech clinical services (equipment) and hospital performance, particularly clinical quality and financial performance. Non-US publications were excluded because 


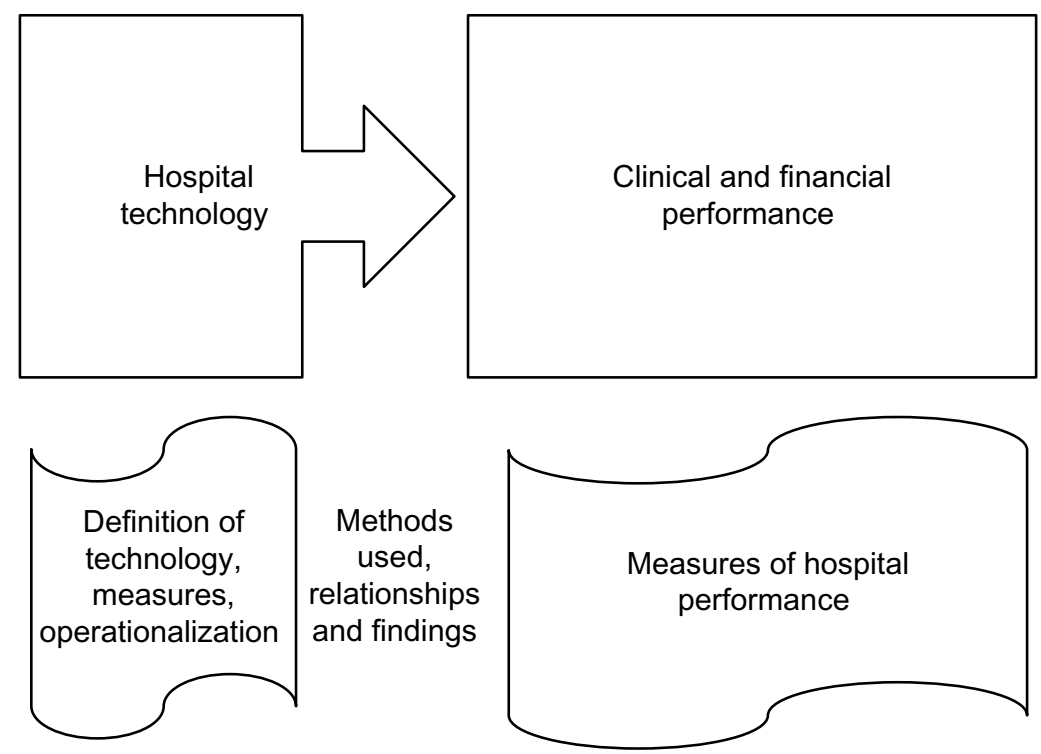

Figure I Analytical framework for the relationship between hospital technology and performance.

of differing regulatory and market environments in other countries. Single-hospital studies were also excluded due to the limited generalizability of their findings.

Second, search terms were identified based on the authors' own expertise, two books on medical technology, ${ }^{2,23}$ several seminal articles on health care technology, ${ }^{1,24-26}$ and several seminal articles on quality and financial performance..$^{21,27,28}$ After conducting a pilot search in PubMed and searching the PubMed MeSH terms, the following keywords and phrases were used in this review: 1) for the technology dimension "hospital", "technology", "high-tech", "equipment", "service line", "service mix", "service offering", "full service", and "hospital service"; and 2) for the performance dimension "quality", "mortality", "readmission", "outcome", "hospital performance", "performance", “cost”, "financial performance", and "financial".

Third, multiple searches were performed by using the keyword combinations in four data search engines (see Figure S1 for keyword combinations). To improve the manageability and relevancy of the results, several filters were used to limit publications to those that: 1) were published in English between 1980 and July 2012; and 2) had key words in the abstract and/or title. A total of 21,682 articles were retrieved from these searches including 12,361 from PubMed; 6,527 from the Web of Science; 994 from Business Source Premier; and 1,800 from the Cumulative Index to Nursing and Allied Health (CINAHL). Thomson Reuters' EndNote was used to aggregate the search results and to screen for duplicates. After eliminating the 7,046 duplicate articles, initial results returned 14,636 articles.
Fourth, to improve the search/selection/retention process and achieve the ultimate focus of this review, a prioridetermined exclusion/inclusion criteria were applied at three stages: 1) criteria stage one removed publications that were not relevant to hospital performance (ie, financial or clinical);2) criteria stage two screened features of publications according to a priori criteria (ie, paper type, unit of analysis, location, and relevancy); and 3) criteria stage three confirmed the presence of clinical technology, hospital performance measures, and the relationship between these two variables.

Figure 2 summarizes the selection process for identifying published studies that investigated the relationship between hospital technology and performance. After applying the three-staged inclusion/exclusion criteria and adding manually searched articles, the number of articles for full-text review was reduced from 14,636 to 288. Following a full text review, 24 publications were abstracted. To strengthen the review search process, the reference section of each abstracted publication was also screened for the inclusion of any potentially relevant publication that might have been missed during earlier steps. Two additional articles were included among the abstracted ones, resulting in 26 empirical articles for this review study.

\section{Results}

The results of this literature review of hospital technology and performance are summarized in Table 1 (financial performance) and Table 2 (clinical performance). Overall, the studies showed mixed results. This is not surprising since the reviewed 


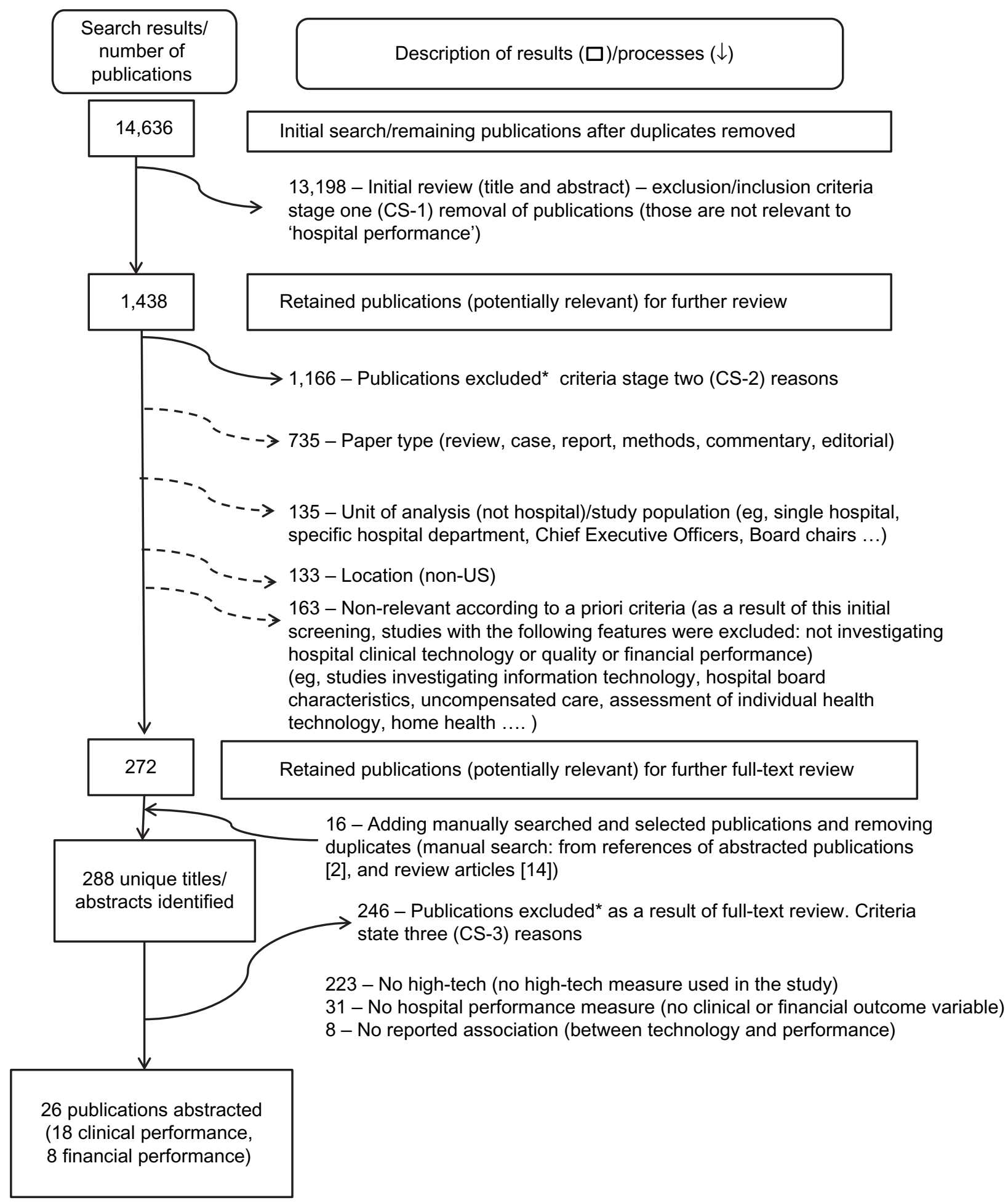

Figure 2 Selection of publications investigating the relationship between hospital technology and performance.

Note: *Exclusions are not mutually exclusive.

studies use a variety of technology and performance measures, as well as different analytical methods. Moreover, technology was not the main focus in most of these studies; instead, technology measures were typically included as a control variable within a study investigating another research topic.
There were also differences across the research studies in terms of their measures of hospital technology (Tables 1 and 2). Out of the 26 publications, seven used one or two technological services as a marker of hospital technology; ${ }^{29-35} 14$ publications used an index of three or 


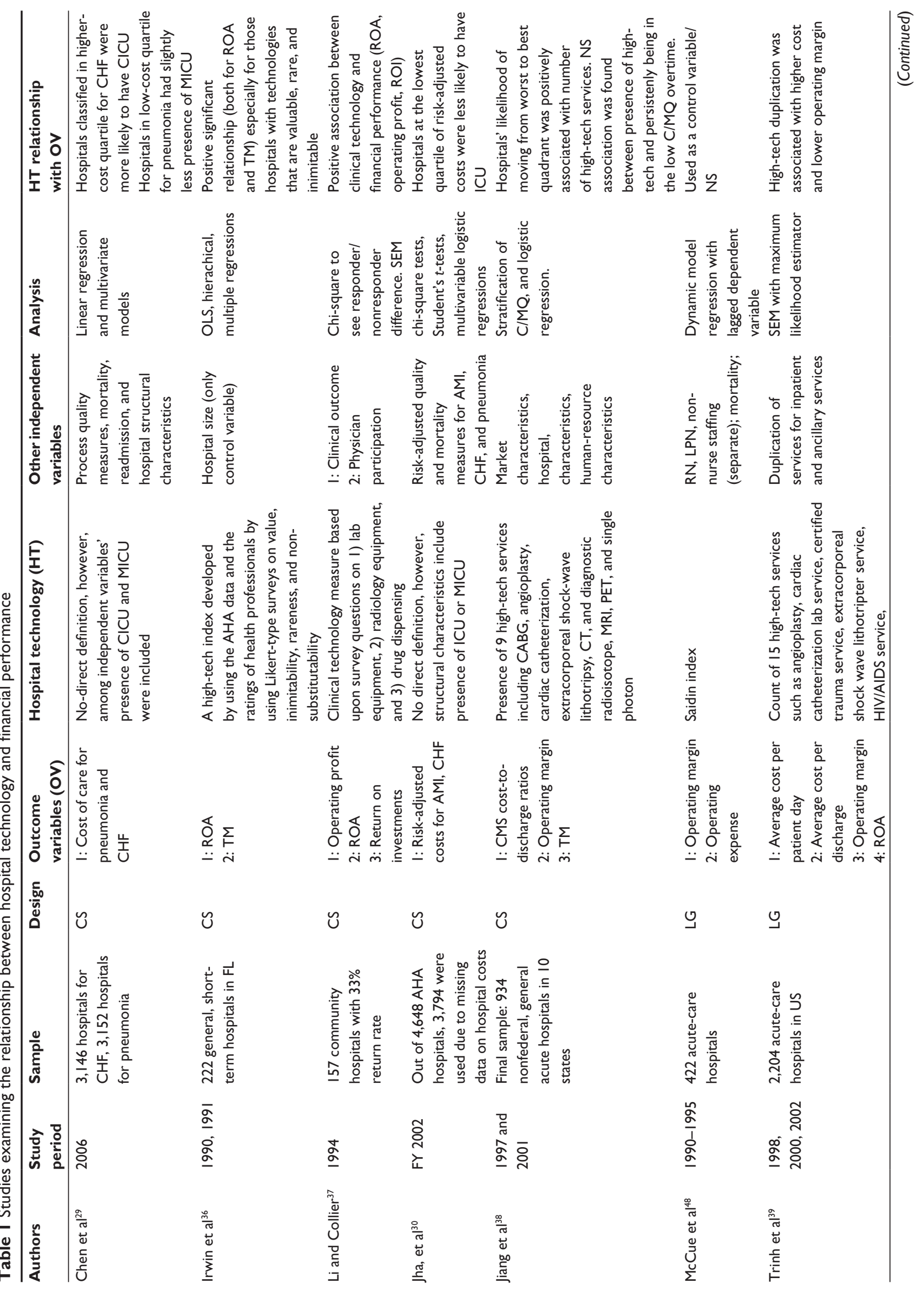




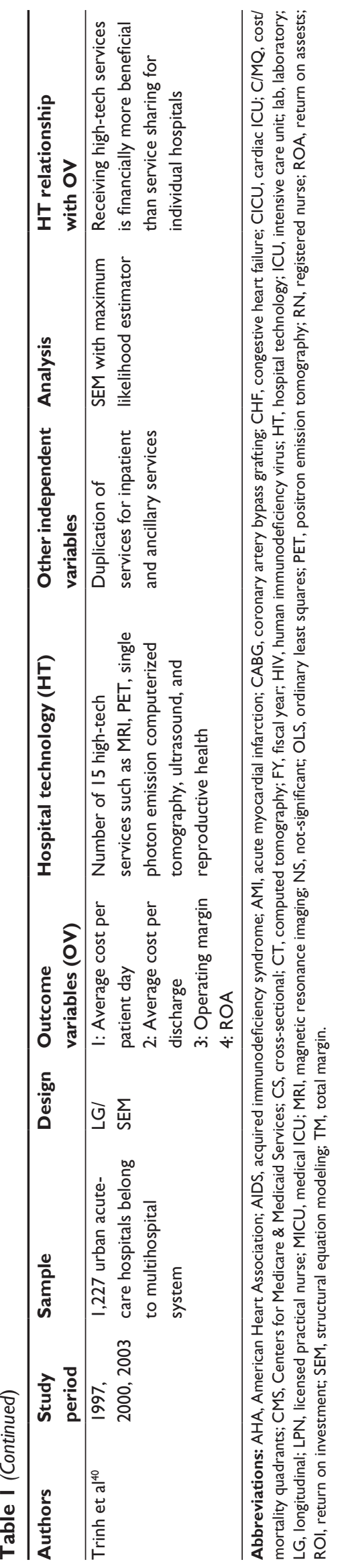

more technological services; $;^{36-47}$ and five publications, all with a nursing focus, used the Saidin index, a special hightech index that takes into account both the breadth and rareness of high-tech services. ${ }^{48-52}$

Eight studies investigated the technology-financial performance link, again with differing research designs, sample sizes, and study periods (Table 1), and mixed results. Four of the eight studies analyzed longitudinal data. ${ }^{25,28-30}$ On one hand, a cross-sectional study found a positive relationship between a technology index and financial performance (return on assets [ROA] and total margin), ${ }^{36}$ on the other hand, a longitudinal study found a nonsignificant relationship for ROA and operating expenses as financial performance measures. ${ }^{48}$ Both studies developed their technology indices by using the American Hospital Association's annual survey. Both studies also used similar profitability measures as dependent variables such as total margin, operating margin, and ROA.

Some of the results indicate an association between the availability of technologies and higher costs at hospitals. For example, a cross-sectional study that used a cardiac intensive care unit and a medical intensive care unit as markers of technological sophistication found that hospitals with a cardiac intensive care unit/medical intensive care unit were in the highest cost quartile for congestive heart failure/pneumonia. ${ }^{29}$ Similarly, a cross-sectional study found that hospitals classified at the lowest risk-adjusted cost quartile for acute myocardial infarction, congestive heart failure, and pneumonia were less likely to have an intensive care unit. ${ }^{30}$

There were 18 studies analyzing the association between hospital technology and clinical performance, also with mixed results (Table 2). The majority $(70 \%)$ of studies in Table 2 used cross-sectional designs, with sample sizes ranging from 54 to 4,401 hospitals. Mortality rate was one of the most frequently used outcome measures. Overall, of the nine studies that used mortality as an outcome, four studies found no significant relationship; four studies found significant and negative relationships; and one study found a significant and positive association between high-tech medical services and mortality rates. Two cross-sectional studies ${ }^{41,49}$ and one longitudinal study ${ }^{44}$ found nonsignificant relationships for mortality rates. Two cross-sectional studies found significant and negative associations between hospital technology and mortality rates, ${ }^{42,47}$ while a longitudinal study found significant and positive association by using ordinary least squares. ${ }^{52}$ For the technology-mortality link in highmanaged-care-penetrated markets, a longitudinal study found significant and positive association by using ordinary least squares, and a significant and negative association by using 


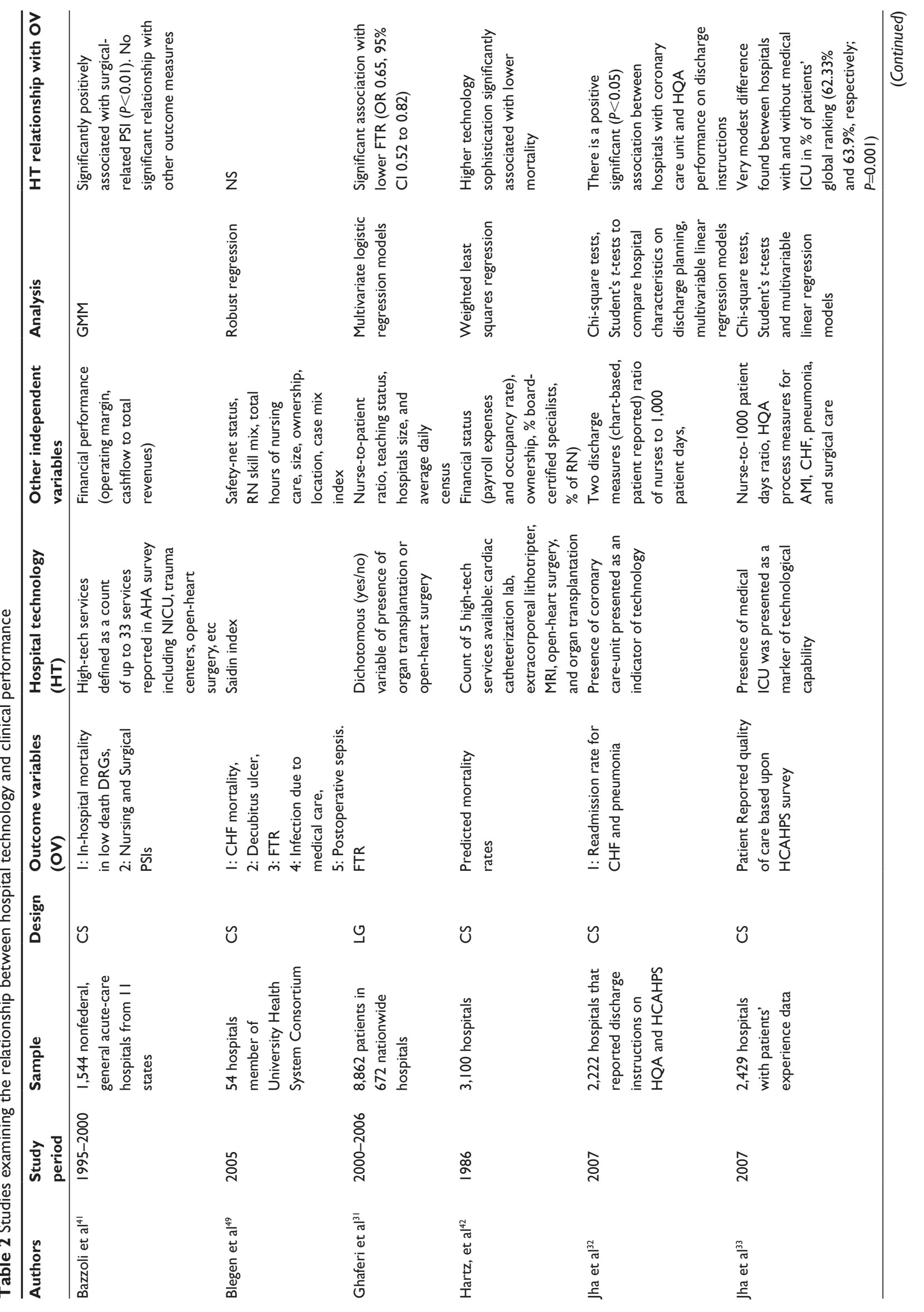




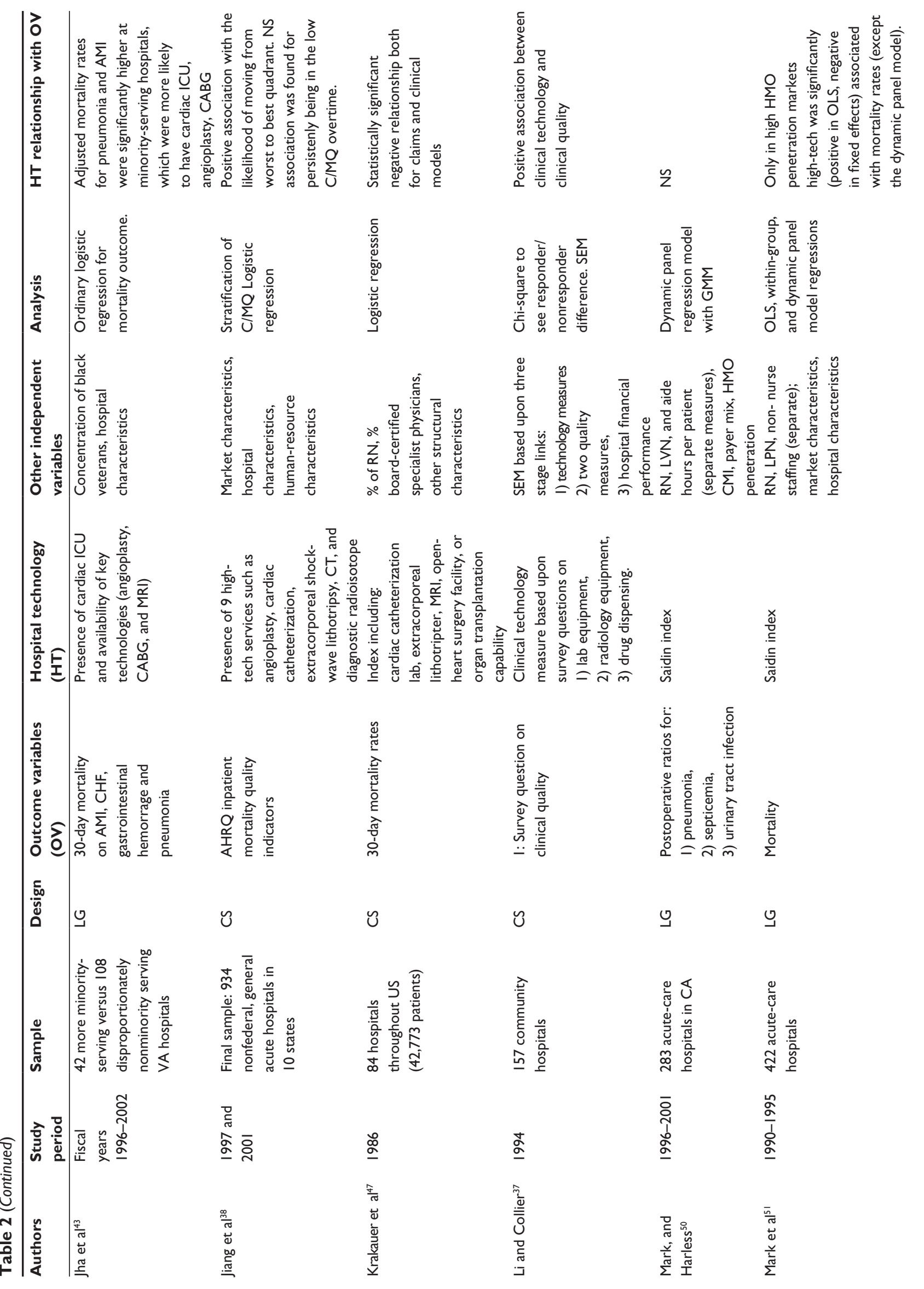



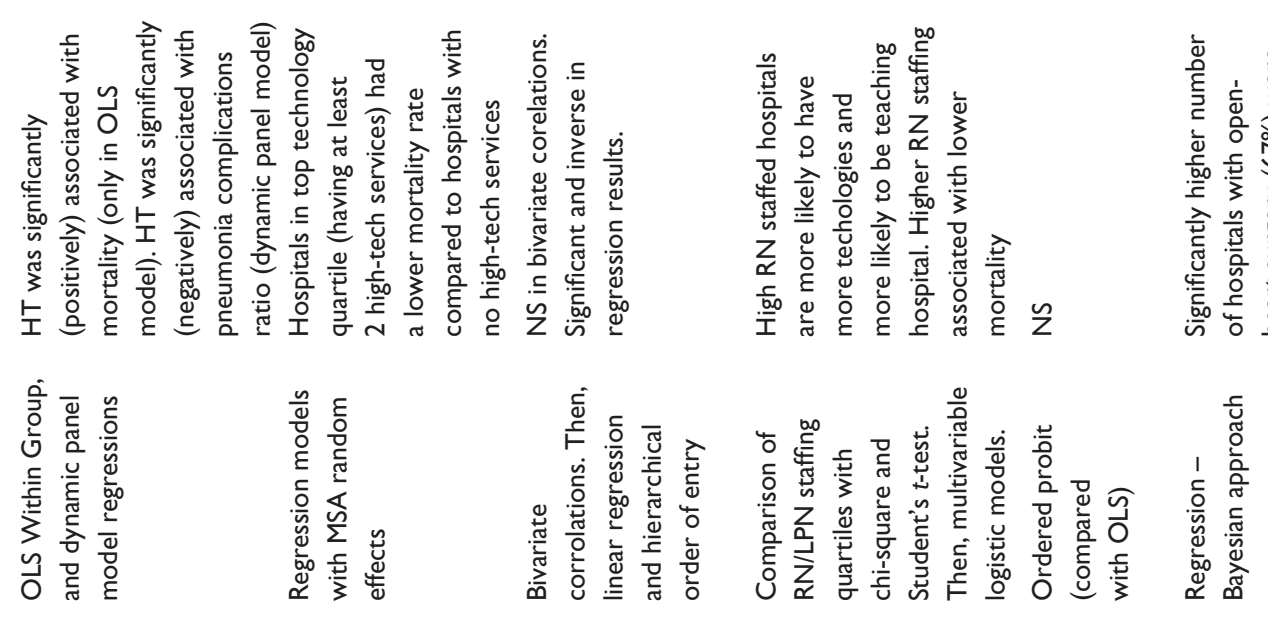

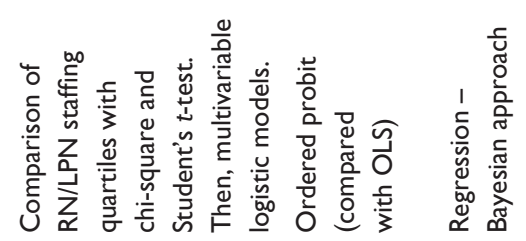
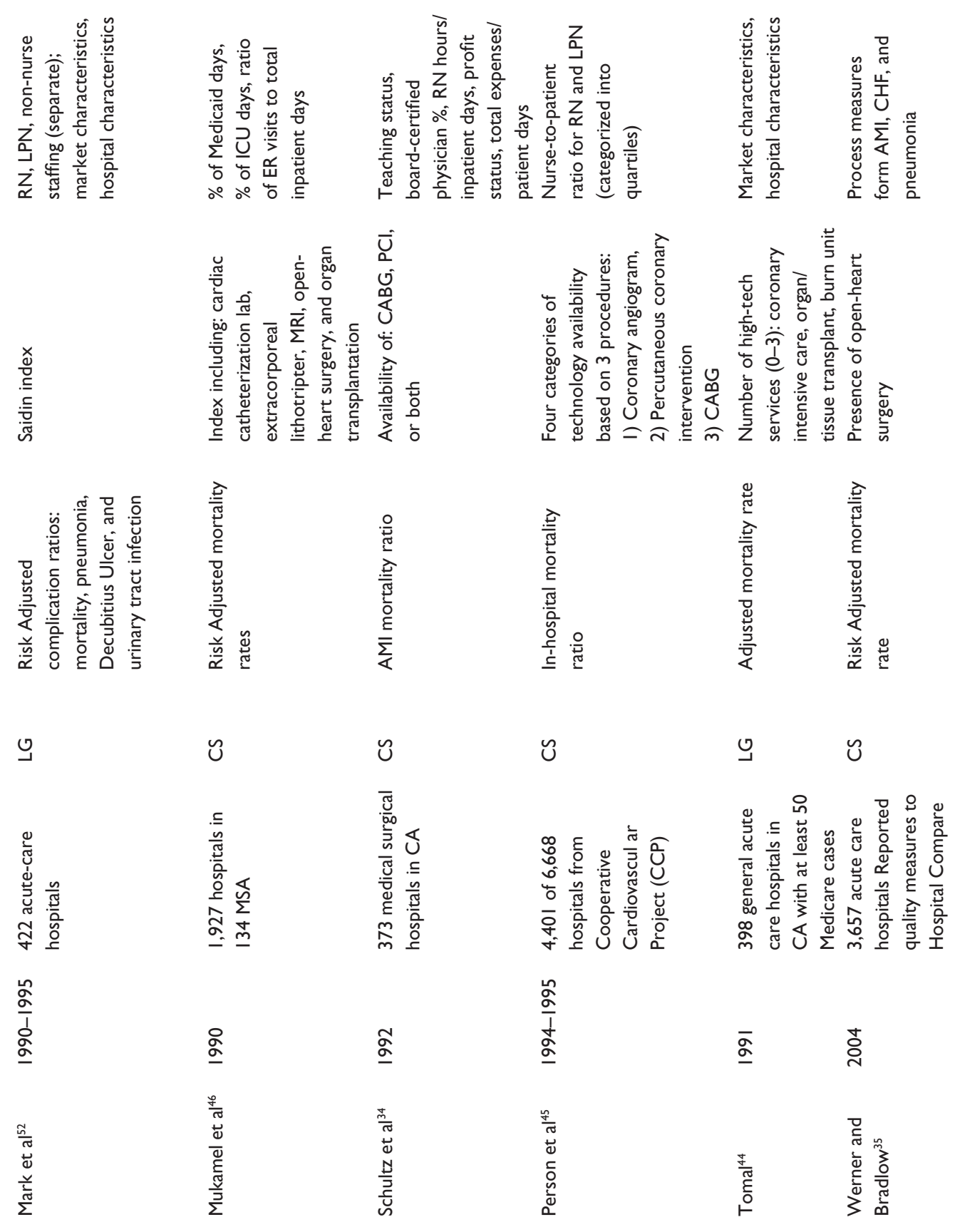
a within-group fixed effects model. ${ }^{51}$ For the relationship between technology and mortality from acute myocardial infarction, a cross-sectional study found a significant and negative association. ${ }^{34}$

Results were also mixed for the link between technology and failure to rescue. For example, a cross-sectional study employing the Saidin index found a nonsignificant association; ${ }^{49}$ in contrast, a longitudinal study using technology measures based upon organ transplantation and open-heart surgery found a significant and negative association. $^{31}$

\section{Discussion and future directions}

In this systematic review, we summarized the findings from 26 empirical studies on the relationship between hospital technology and performance in the US. Several findings were revealed. First, the studies exhibited mixed and, in some cases, contradictory results regarding the relationship between hospital technology and performance (clinical and financial). In particular, this was observed for mortality (clinical measure) and ROA (financial performance measure). However, the variation in technology measures and study designs limits the comparability across studies. Therefore, based upon this review, there is no clear evidence for either positive or negative relationships between high-tech services and hospital performance.

Second, the number of empirical studies investigating the relationship between hospital technology and performance is very limited. Of the 26 abstracted publications, technology was the focus in only two of these studies ${ }^{36,37}$ and only eight studies included financial performance measures. Given the increasing adoption of technological innovations, further research is needed to understand the implications of technology adoption on hospitals' clinical and financial performance.

Third, the generalizability and comparability of these 26 studies are constrained due to some methodological limitations. For example, the generalizability of the findings of two technology-focused publications were limited since one study ${ }^{37}$ relied solely on cross-sectional survey data, while the other study ${ }^{36}$ relied on cross-sectional data from only one state (Florida).

In summary, more evidence is needed to clarify the technology-performance link, especially when hospitals may be moving into another medical arms-race era. ${ }^{53}$ In the medical arms-race era prior to the prospective payment system in 1983, hospitals exhibited uncontrolled and unplanned competitive behaviors by adopting various services and tech- nologies to attract patients and physicians. ${ }^{39}$ Such competitive behavior may not only increase health care costs, but may also substantially reduce the financial performance of hospitals. Trinh et $\mathrm{al}^{39}$ found that high-tech service duplication in a hospital market was associated with higher costs and lower operating margins. However, they also found that high-tech service duplication was associated with higher occupancy rates, indicating the legitimacy of strategically using technology to attract patients. Therefore, future research should not only examine the relationship between hospital technology and performance, but should also provide managers with insights into achieving a balance between the costs and benefits of hospital technologies. Besides the aforementioned future direction, we also have several recommendations for future studies.

The first recommendation pertains to the recognition of the intricate relationship between hospital technology and performance, and the development of strategies to effectively measure these independent and dependent variables. One of the difficulties in evaluating the influence of technology on hospital performance is accounting for the many confounding organizational, operational, and market characteristics. Moreover, as a structural component, the outcomes of hospital technologies are moderated/mediated by the processes of care. Processes of care and operations are provided by the human capital of the organization. Therefore, future studies should consider more robust research designs that acknowledge both human and operational characteristics of organizations, in addition to market and organizational characteristics.

The second recommendation is with respect to the development of hospital technology measures. Our review confirmed Spetz and Maiuro's ${ }^{1}$ conclusion about the lack of standardized methods for defining, conceptualizing, and measuring hospital technology (Tables 1 and 2). Hospital technologies have been defined and conceptualized in various ways that span from one technology as a marker to sophisticated technology indices, such as the Saidin index. Not having reliable and consistent technology measures makes it very difficult to draw inferences, generalize findings, and perform comparisons across studies. Therefore, future studies should test the reliability and strengths/weaknesses of existing technology measures in different settings and study periods, and adapt existing technology measures as new technologies arise.

The third recommendation calls for examining the organizational and societal implications of hospital technologies. Societal implications of hospital technologies, such as welfare 
benefit or loss, build upon organizational and individual impacts of those technological services. However, these societal implications may not be the simple cumulative forms of organizational/individual impacts. For example, in order to understand the societal cost implications of technologies, one should consider also the market forces. Newhouse, in his seminal 1992 article, identifies medical technologies as the largest contributor of rising health care cost in the United States after discussing several other plausible options. He supports his claim by pointing out the fact that the largest portion of rising health care cost is attributed to hospital expenditures, and technological change seems to represent the bulk of these hospital expenditures. ${ }^{3}$ Others argue that the societal benefits of hospital clinical technologies exceed their costs. ${ }^{4,54,55}$ Regardless of the position one may take, further research is needed to understand both the organizational and societal cost-benefit implications of hospital-based clinical technologies.

The fourth recommendation relates to the availability and dissemination of the hospital technology-performance research. Currently, the United States lacks a coordinated technology planning and assessment process. ${ }^{56}$ The efficient use of the nation's limited resources may be impeded by the uncoordinated adoption of high-cost medical technologies. A hospital's adoption decision for a technology independent of another hospital might cause service duplication in the market, which may translate into underutilization, excess capacity, and operational and financial inefficiencies. The Affordable Care Act provides increased funding for training and research on the comparative effectiveness of different technologies. Increased availability and dissemination about the pros and cons of medical technologies has the potential to improve the market efficiency.

The fifth recommendation focuses on improving hospitalbased clinical technology data collection and methods. The development of high-quality information requires the availability of high-quality data for analysis. Hospital performance researchers build their research according to their research objectives and the availability of data. However, the increasing number of sophisticated clinical technologies and the problems with cross-sectional data collection methods make it difficult to find reliable data, especially on hospitalbased clinical technologies. ${ }^{1}$ Thus, future policies should also address the generation of reliable data sources to improve knowledge about the relationship between hospital-based clinical technology and performance.

This review has several limitations. First, since clinical technology was not the main predictor of interest for most of the abstracted publications, we may have missed articles in which technology was not recognized in either the title or the abstract. Second, limitations might have arisen as a result of the keyword selection, search engines, or the search process itself. However, we attempted to diminish this bias by adding the review of manually selected publications from the bibliographies of two related books, including several review articles, and subjecting the abstracted articles to the snowball technique in an attempt to identify studies. Third, because this review article focused only on hospitals' clinical quality and financial performance, it does not address the consumer's perceptions about quality. Given the importance of consumer perceptions about high-technology clinical services, future reviews may consider focusing on consumer's perceptions of quality and investigate the relationships between high-technology clinical services and hospital performance.

Despite these limitations, this is the first review that attempts to summarize the literature on the relationship between hospitals' clinical technology and performance at the organizational level. Although there are many studies that investigate the cost-benefit implications of individual technologies, organizational-level research on the net benefits of high-tech services vis-à-vis their costs is limited. Given the strategic importance of hospital-based clinical technology, further research is needed to inform policymakers about their impact on organizational costs and quality.

\section{Disclosure}

The authors report no conflicts of interest in this work.

\section{References}

1. Spetz J, Maiuro LS. Measuring levels of technology in hospitals. The Quarterly Review of Economics and Finance. 2004;44(3):430-447.

2. Callahan D. Taming The Beloved Beast How Medical Technology Costs are Destroying Our Health Care System. Princeton, NJ: Princeton University Press; 2009.

3. Newhouse JP. Medical care costs: how much welfare loss? J Econ Perspect. 1992;6(3):3-21.

4. Newhouse JP. An iconoclastic view of health cost containment. Health Aff (Millwood). 1993;12 Suppl:152-171.

5. Peden EA, Freeland MS. A historical analysis of medical spending growth, 1960-1993. Health Aff (Millwood). 1995;14(2):235-247.

6. Reynolds BL. The delivery of medical care and institutional change. J Econ Issues. 1989;23(1):215.

7. Scitovsky AA. Changes in the costs of treatment of selected illnesses, 1971-1981. Med Care. 1985;23(12):1345-1357.

8. Connors AF Jr, Speroff T, Dawson NV, et al. The effectiveness of right heart catheterization in the initial care of critically ill patients. SUPPORT Investigators. JAMA. 1996;276(11):889-897.

9. Berger RA, Jacobs JJ, Meneghini RM, Della Valle C, Paprosky W, Rosenberg AG. Rapid rehabilitation and recovery with minimally invasive total hip arthroplasty. Clin Orthop Relat Res. 2004;(429):239-247.

10. Grossman JM, Banks DA. Unrestricted Entry and Nonprice Competition: The case of Technological Adoption in Hospitals. International Journal of Economics of Business. 1998;5(2):223-269. 
11. Baker LC, Phibbs CS. Managed care, technology adoption, and health care: the adoption of neonatal intensive care. Rand J Econ. 2002;33(3): 524-548.

12. Zhang N, Kohn L, McGarrah R, Anderson G. The effect of managed care on hospital staffing and technological diffusion. Health Policy. 1999;48(3):189-205.

13. Hartley D, Moscovice I, Christianson J. Mobile technology in rural hospitals: the case of the CT scanner. Health Serv Res. 1996;31(2): 213-234.

14. Teplensky JD, Pauly MV, Kimberly JR, Hillman AL, Schwartz JS. Hospital adoption of medical technology: an empirical-test of alternative models. Health Serv Res. 1995;30(3):437-465.

15. Escarce JJ. Externalities in hospitals and physician adoption of a new surgical technology: an exploratory analysis. J Health Econ. 1996;15(6):715-734.

16. Retel VP, Hummel MJ, van Harten WH. Early phase Technology Assessment of nanotechnology in oncology. Tumori. 2008;94(2):284-290.

17. Vanderveen KA, Paterniti DA, Kravitz RL, Bold RJ. Diffusion of surgical techniques in early stage breast cancer: variables related to adoption and implementation of sentinel lymph node biopsy. Ann Surg Oncol. 2007;14(5):1662-1669.

18. Morris DS, Miller DC, Hollingsworth JM, et al. Differential adoption of laparoscopy by treatment indication. J Urol. 2007;178(5):2109-2113.

19. Miller DC, Taub DA, Dunn RL, Wei JT, Hollenbeck BK. Laparoscopy for renal cell carcinoma: diffusion versus regionalization? J Urol. 2006;176(3):1102-1106.

20. Donabedian A. Criteria, norms and standards of quality: what do they mean? Am J Public Health. 1981;71(4):409-412.

21. Donabedian A. Methods for deriving criteria for assessing the quality of medical care. Med Care Rev. 1980;37(7):653-698.

22. Donabedian A. Evaluating the quality of medical care. Milbank Mem Fund Q. 1966;44(3):Suppl:166-206.

23. Cohen AB, Hanft RS. Technology in American Health Care: Policy Directions for Effective Evaluation and Management. Ann Arbor: The University of Michigan Press; 2004.

24. Acemoglu D, Finkelstein A. Input and Technology Choices in Regulated Industries: Evidence from the Health Care Sector. J Polit Econ. 2008;116(5):837-880.

25. Chernew ME, Hirth RA, Sonnad SS, Ermann R, Fendrick AM. Managed care, medical technology, and health care cost growth: a review of the evidence. Med Care Res Rev. 1998;55(3):259-288; discussion 289-297.

26. Morrisey MA. Competition in hospital and health insurance markets: a review and research agenda. Health Serv Res. 2001;36(1 Pt 2): 191-221.

27. Hearld LR, Alexander JA, Fraser I, Jiang HJ. Review: how do hospital organizational structure and processes affect quality of care? a critical review of research methods. Med Care Res Rev. 2008;65(3):259-299.

28. Pink GH, Holmes GM, D’Alpe C, Strunk LA, McGee P, Slifkin RT. Financial indicators for critical access hospitals. J Rural Health. 2006;22(3):229-236.

29. Chen LM, Jha AK, Guterman S, Ridgway AB, Orav EJ, Epstein AM. Hospital cost of care, quality of care, and readmission rates: penny wise and pound foolish? Arch Intern Med. 2010;170(4):340-346.

30. Jha AK, Orav EJ, Dobson A, Book RA, Epstein AM. Measuring efficiency: the association of hospital costs and quality of care. Health Aff (Millwood). 2009;28(3):897-906.

31. Ghaferi AA, Osborne NH, Birkmeyer JD, Dimick JB. Hospital characteristics associated with failure to rescue from complications after pancreatectomy. J Am Coll Surg. 2010;211(3):325-330.

32. Jha AK, Orav EJ, Epstein AM. Public reporting of discharge planning and rates of readmissions. $N$ Engl J Med. 2009;361(27):2637-2645.

33. Jha AK, Orav EJ, Zheng J, Epstein AM. Patients' perception of hospital care in the United States. N Engl J Med. 2008;359(18):1921-1931.

34. Schultz MA, van Servellen G, Litwin MS, McLaughlin EJ, Uman GC. Can hospital structural and financial characteristics explain variations in mortality caused by acute myocardial infarction? Appl Nurs Res. 1999;12(4):210-214.
35. Werner RM, Bradlow ET. Relationship between Medicare's hospital compare performance measures and mortality rates. JAMA. 2006;296(22):2694-2702.

36. Irwin JG, Hoffman JJ, Lamont BT. The effect of the acquisition of technological innovations on organizational performance: A resourcebased view. Journal of Engineering and Technology Management. 1998;15(1):25-54.

37. Li LX, Collier DA. The role of technology and quality on hospital financial performance: An exploratory analysis. International Journal of Service Industry Management. 2000;11(3):202-224.

38. Jiang HJ, Friedman B, Begun JW. Sustaining and improving hospital performance: The effects of organizational and market factors. Health Care Manage Rev. 2006;31(3):188-196.

39. Trinh HQ, Begun JW, Luke RD. Hospital service duplication: evidence on the medical arms race. Health Care Manage Rev. 2008;33(3):192-202.

40. Trinh HQ, Begun JW, Luke RD. Better to receive than to give? Interorganizational service arrangements and hospital performance. Health Care Manage Rev. 2010;35(1):88-97.

41. Bazzoli GJ, Chen HF, Zhao M, Lindrooth RC. Hospital financial condition and the quality of patient care. Health Econ. 2008;17(8):977-995.

42. Hartz AJ, Krakauer H, Kuhn EM, et al. Hospital characteristics and mortality rates. $N$ Engl J Med. 1989;321(25):1720-1725.

43. Jha AK, Stone R, Lave J, Chen H, Klusaritz H, Volpp K. The concentration of hospital care for black veterans in Veterans Affairs hospitals: implications for clinical outcomes. J Healthc Qual. 2010;32(6):52-61.

44. Tomal A. The relationship between hospital mortality rates, and hospital, market and patient characteristics. Appl Econ. Jun 1998;30(6): 717-725.

45. Person SD, Allison JJ, Kiefe CI, et al. Nurse staffing and mortality for Medicare patients with acute myocardial infarction. Med Care. 2004;42(1):4-12.

46. Mukamel DB, Zwanziger J, Tomaszewski KJ. HMO penetration, competition, and risk-adjusted hospital mortality. Health Serv Res. 2001;36(6 Pt 1):1019-1035.

47. Krakauer H, Bailey RC, Skellan KJ, et al. Evaluation of the HCFA model for the analysis of mortality following hospitalization. Health Serv Res. 1992;27(3):317-335.

48. McCue M, Mark BA, Harless DW. Nurse staffing, quality, and financial performance. J Health Care Finance. 2003;29(4):54-76.

49. Blegen MA, Goode CJ, Spetz J, Vaughn T, Park SH. Nurse staffing effects on patient outcomes safety-net and non-safety-net hospitals. Med Care. 2011;49(4):406-414.

50. Mark BA, Harless DW. Nurse staffing and post-surgical complications using the present on admission indicator. Res Nurs Health. 2010;33(1): $35-47$.

51. Mark BA, Harless DW, McCue M. The impact of HMO penetration on the relationship between nurse staffing and quality. Health Econ. 2005;14(7):737-753.

52. Mark BA, Harless DW, McCue M, Xu Y. A longitudinal examination of hospital registered nurse staffing and quality of care. Health Serv Res. 2004;39(2):279-300.

53. Devers KJ, Brewster LR, Casalino LP. Changes in hospital competitive strategy: a new medical arms race? Health Serv Res. 2003;38(1 Pt 2): 447-469.

54. Cutler TW, Palmieri J, Khalsa M, Stebbins M. Evaluation of the relationship between a chronic disease care management program and california pay-for-performance diabetes care cholesterol measures in one medical group. J Manage Care Pharm. 2007;13(7):578-588.

55. Cutler DM, McClellan M. Is technological change in medicine worth it? Health Aff (Millwood). 2001;20(5):11-29.

56. Coye MJ, Kell J. How hospitals confront new technology. Health Aff (Millwood). 2006;25(1):163-173. 


\section{Supplementary material}

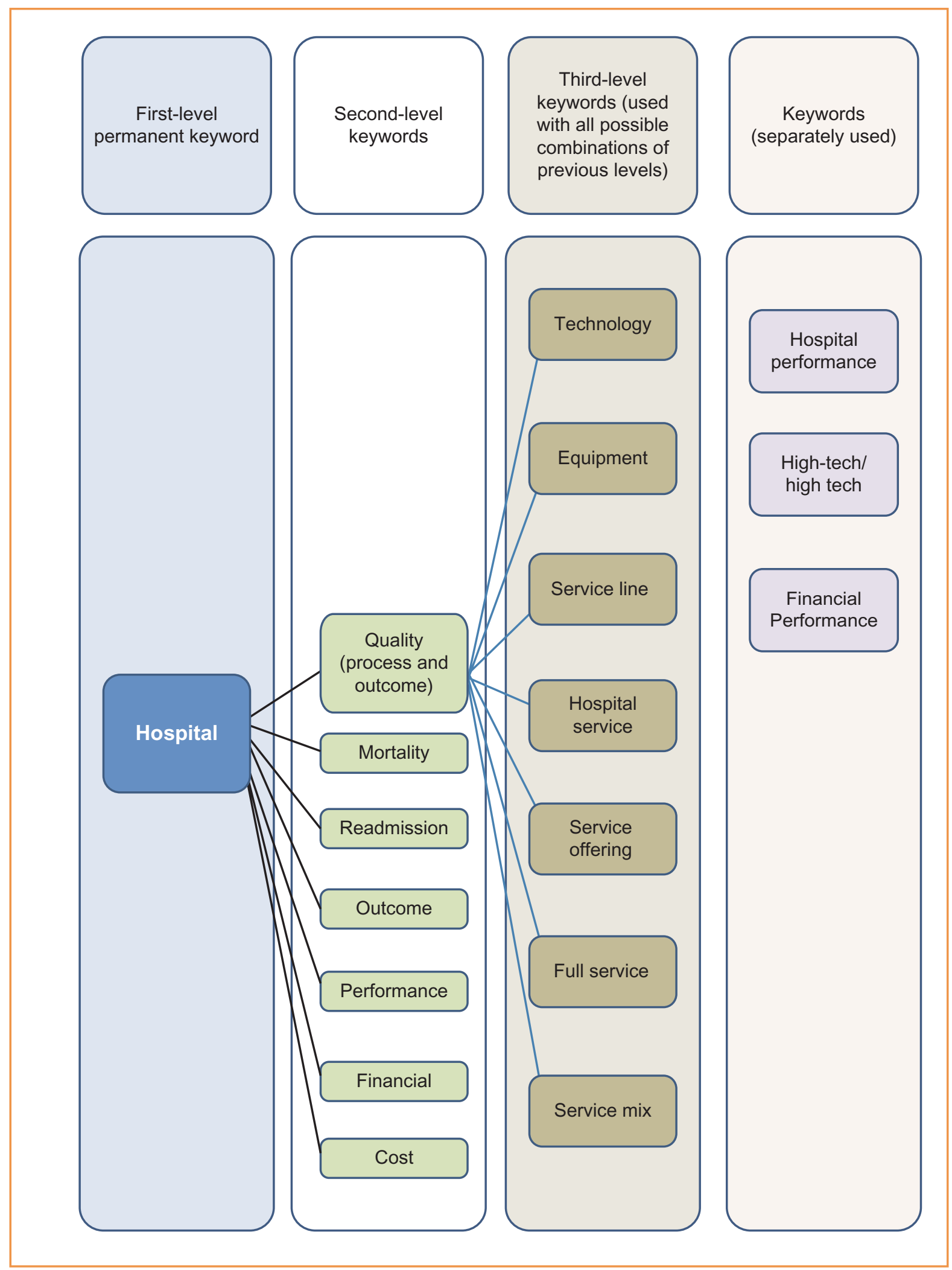

Figure SI Keyword combinations. 
Innovation and Entrepreneurship in Health

Dovepress

\section{Publish your work in this journal}

Innovation and Entrepreneurship in Health is an international, peer reviewed, open access journal publishing original research, reports, reviews and commentaries on innovation and entrepreneurship in health. Special focus will be given to the theory, process, and practice of innovation and entrepreneurship by individuals and organizations

within the health care context globally. The manuscript management system is completely online and includes a very quick and fair peer review system, which is all easy to use. Visit http://www.dovepress.com/ testimonials.php to read real quotes from published authors.

Submit your manuscript here: http://www.dovepress.com/innovation-and-entrepreneurship-in-health-journal 